'Fancourt R, Campbell S, Harvey D, Norman AP. Follow-up study of small-for-dates babies. Br Med $\mathcal{F} 1976$; i :1435-7.

${ }^{6}$ Walther FJ, Ramaekers LHJ. Growth in early childhood of newborns affected by disproportionate intrauterine growth retardation. Acta Paediatr Scand 1982;71:651-6.

${ }^{7}$ Fledelius HC. Inhibited growth and development as permanent features of low birth weight. A longitudinal study of eye size, height, head circumference, interpupillary distance and exophthalmometry, as measured at age of 10 and 18 years. Acta Paediatr Scand 1982;71:645-50.

\section{Tuberculosis: who should prescribe?}

The welcome decline in the number of patients suffering from tuberculosis in many countries, including Britain, has made experience in the diagnosis and management of the disease more difficult to obtain. Newly graduated doctors may have seen little or no tuberculous disease during their undergraduate years. A recent study in North America showed that there were prescription errors in over half the cases treated by recently qualified non-respiratory physicians, with the blame being placed (in part) on inadequacies in medical school curricula. ${ }^{1}$

The $B M F$ has recently published three retrospective accounts of the routine clinical treatment of tuberculosis, one dealing with pulmonary ${ }^{2}$ and two with non-pulmonary disease. $^{3} 4$ Wardman et al specifically identified therapeutic errors in 10 patients, all of whom began inappropriate chemotherapy given by non-respiratory physicians. ${ }^{3}$ In two patients the errors made were gross; one died later from extensive renal tuberculosis, and the other relapsed six years later with cryptic miliary tuberculosis. A third patient suffered from severe peripheral neuropathy as a result of an excessive dose of isoniazid given during six weeks' treatment. The remaining seven patients were apparently cured despite the fact that only one received a regimen acceptable in type and duration. Isoniazid was sometimes given in divided doses, excessive doses, or inadequate doses; rifampicin was given in too low a dose or the timing of administration of the drug was incorrect; and ethambutol and streptomycin were given in divided doses. The authors concluded that "there is a strong argument for all cases of tuberculosis to be referred to a respiratory physician for chemotherapeutic management from the outset." Woodroffe has disputed this conclusion, arguing that the problem is not one of lack of special knowledge but failure to look up the proper dose of the $\operatorname{drug}(\mathrm{s})$ being prescribed. ${ }^{5}$

The problem of who should treat tuberculosis is not as clear cut as either Woodroffe ${ }^{5}$ or Wardman et $a l^{3}$ suggest. The treatment of tuberculosis is a question not only of drugs and dosage, but very importantly of regimens and the duration of treatment. Accurate information on the doses and toxicity of antituberculous drugs is given in the British National Formulary, ${ }^{6}$ yet the drugs may still be prescribed wrongly if the introductory paragraphs (which give clear instructions regarding one appropriate regimen) are missed.

With the decline in the prevalence of tuberculosis in many countries family doctors and many hospital clinicians may be called on to treat one or two or even fewer patients in a year. The occasional prescriber would therefore be well advised to seek the advice of the chest physician-who may be as vulnerable to error as any other clinician but is familiar with effective regimens in varying circumstances and with the minutiae of drug toxicity. Such knowledge is necessary to ensure total success in compliant patients.

As McLarty has pointed out, however, in large areas of the world specialist physicians are few and far between. ${ }^{7}$ Errors of treatment are rarely seen in these areas-because a simple standardised treatment course is used. Perhaps there is a message there for the developed countries.

NORMAN HORNE

Consultant Physician

Chest Unit,

City Hospital,

Edinburgh EH10 5SB

${ }^{1}$ Byrd RB, Horne BR, Solomon DA, Griggs GA, Wilder NJ. Treatment of tuberculosis by the nonpulmonary physician. Ann Intern Med $1977 ; 86: 799-802$.

${ }^{2}$ Monie RDH, Hunter AM, Rocchiccioli K, White J, Campbell IA, Kilpatrick GS. Survey of pulmonary tuberculosis in south and west Wales (1976-8). Br Med F 1982;284:571-3.

3 Wardman AG, Williams SE, Curzon PGD, Page RL, Cooke NJ. Tuberculosis: who should prescribe? $\mathrm{Br}$ Med 7 1982;284:569-70.

4 Monie RDH, Hunter AM, Rocchiccioli KMS, White JP, Campbell IA, Kilpatrick GS. Management of extra-pulmonary tuberculosis (excluding miliary and meningeal) in south and west Wales (1976-8). $\mathrm{Br} \mathrm{Med} \mathscr{f}$ $1982 ; 285: 415-8$.

5 Woodroffe FJ. Tuberculosis: who should prescribe? $\mathrm{Br}$ Med $\mathcal{F}$ 1982; $284: 1046$.

British Medical Association, Pharmaceutical Society. British national formulary. No 4. London: British Medical Association, Pharmaceutical Society, 1982.

${ }^{7}$ McLarty DG. Tuberculosis: who should prescribe ? $\mathrm{Br} M e d f 1982$; 284:1196.

\section{Legislation and medical ethics}

One of the most difficult dilemmas in medical ethics is the apparent conflict between the principles of confidentiality and public safety. In Britain the medical profession has been fortunate in that, until now, Parliament has been very reluctant to enact legislation that would compel doctors to disclose information without the consent of the patient. In exercising their power of subpoena, whether of medical records or of a doctor as a witness, the courts are always ready to listen to objections and explanations from a doctor about why a particular piece of evidence should not be disclosed, and judges will often uphold the doctor's objection and refuse to order him to disclose that evidence.

There is no substitute in clinical medicine for careful history taking, and the notes of the patient's previous attendances, investigations, and treatment are essential for decisions. The knowledge that this information will be disclosed only in the most exceptional circumstances ensures that patients are entirely frank and that doctors keep comprehensive notes. Any relaxation of the traditional safeguards would change these attitudes and create the risk of patients being treated on the basis of incomplete or inaccurate information. That risk explains why the medical profession must examine very closely two Bills recently presented by the Government to Parliament.

The first is the Police and Criminal Evidence Bill, ${ }^{1}$ which is proceeding rapidly through the House of Commons. Clause 10 provides that a circuit judge can issue an order requiring the production of evidence to the police, and in certain circumstances he may issue a warrant to search for it in the case of arrestable offences. A doctor will be given no opportunity, as he has at present, to object to the disclosure of medical records, 